\title{
Liver cancers with stem/progenitor-cell features - a rare chemotherapy-sensitive malignancy
}

\author{
Bruno Christian Köhler ${ }^{1,2}$, Nina Waldburger ${ }^{3,2}$, Kai Schlamp4, Dirk Jäger ${ }^{1,2}$, Karl \\ Heinz Weiss ${ }^{5,2}$, Henning Schulze-Bergkamen ${ }^{6}$, Peter Schirmacher ${ }^{3,2}$ and Christoph \\ Springfeld ${ }^{1,2}$ \\ ${ }^{1}$ Department of Medical Oncology, National Center for Tumor Diseases, University Hospital Heidelberg, Heidelberg, Germany \\ ${ }^{2}$ Liver Cancer Center Heidelberg, University Hospital Heidelberg, Heidelberg, Germany \\ ${ }^{3}$ Institute of Pathology, University Hospital Heidelberg, Heidelberg, Germany \\ ${ }^{4}$ Department of Neuroradiology, University Hospital Heidelberg, Heidelberg, Germany \\ ${ }^{5}$ Department of Gastroenterology, University Hospital Heidelberg, Heidelberg, Germany \\ ${ }^{6}$ Department of Internal Medicine II, Marien-Hospital, Wesel, Germany \\ Correspondence to: Bruno Christian Köhler, email: bruno.koehler@nct-heidelberg.de
}

Keywords: liver cancer, liver stem cell, liver progenitor cell, alpha fetoprotein, chemotherapy

Received: January 18, $2017 \quad$ Accepted: June 14, $2017 \quad$ Published: June 05, 2017

Copyright: Köhler et al. This is an open-access article distributed under the terms of the Creative Commons Attribution License 3.0 (CC BY 3.0), which permits unrestricted use, distribution, and reproduction in any medium, provided the original author and source are credited.

\section{ABSTRACT}

Primary liver tumors are a heterogeneous group of malignancies. Besides classical hepatocellular carcinoma (HCC) and cholangiocarcinoma (CC), combined and intermediate forms of liver cancer exist and can express stem-cell markers like nuclear cell adhesion molecule (NCAM-1/CD56), c-kit (CD117) or epithelial cell adhesion molecule (EPCAM) together with high proliferative activity. Liver tumors with progenitor-cell features are associated with an unfavorable prognosis, but the phenotype has not resulted in therapeutic consequences so far.

We report three patients with liver cancers with stem/progenitor-cell features that responded exceptionally well to chemotherapy. These encouraging results indicate that the identification of liver cancer with stem/progenitor-cell phenotype in a patient' $s$ tumor might justify an attempt to treat the patient with chemotherapy. Further case studies and finally clinical trials will be necessary to determine the optimal treatment for patients with this rare form of liver cancer.

\section{INTRODUCTION}

Hepatobiliary cancer represents a major health issue with increasing mortality [1]. Hepatocellular carcinomas (HCCs) show a poor response to chemotherapy, and multityrosine kinase inhibition, is the only approved systemic treatment option [2]. In contrast, standard treatment for patients with unresectable cholangiocarcinoma (CC) is palliative chemotherapy with cisplatin and gemcitabine, resulting in a median overall survival of 11.7 months compared to 8.1 months for patients treated with gemcitabine alone [3].

Recent insights into the genetics and oncogenic mechanisms of liver carcinogenesis revealed an enormous complexity of $\mathrm{HCC}$ and $\mathrm{CC}$ with overlaps and shared features (reviewed in Sia et al., Gastroenterology 2017) [4]. A pluripotent progenitor cell compartment has been proposed as representing the origin of both, $\mathrm{HCC}$ and CC. The current WHO classification of liver tumors distinguishes HCC and CC from combined HCC-CC with or without stem-cell features. In addition, undifferentiated liver cancer, which also may express stem cell markers is provisionally included into HCC [5]. Retrospective analyses of liver tumors have associated stem/progenitor cell features, i.e. CK19, EpCAM and others with an unfavorable prognosis and a more aggressive clinical course [6-8]. Nevertheless, there has been no translation from this histopathological recognition to a therapeutic consequence. 
Here, we report three patients with liver cancers expressing stem/progenitor markers. For the first time, we delineate a therapeutic approach utilizing poly-chemotherapy. Three patients responded well to chemotherapy, indicating that patients with this rare subgroup of liver cancer might benefit from chemotherapy.

\section{RESULTS}

\section{Patient 1}

An initial 61-years-old Caucasian male was referred to our center for second opinion with the diagnosis of hepatocellular carcinoma that was based on a biopsy of the tumor. He had first presented with painless jaundice and weight loss. Jaundice was caused by compression of the common bile duct and treated with an endoprothesis. The patient had no underlying liver disease and had progressed under first-line therapy with sorafenib. At the time of referral, the patient was in good performance status (ECOG 1, Karnofsky-Index $80 \%$ ) and had no relevant comorbidities. Liver function was not impaired (Table 2). CT-scan showed polytopic tumors in the liver parenchyma (Figure 3A). Because the hepatic lesions did not show typical radiological HCC criteria like arterial enhancement and wash-out in the portal venous phase, the tumor biopsy was re-evaluated. Histomorphology showed solid growing tumor nests consisting of medium-sized tumor cells with moderate nuclear atypia. Immunohistochemistry revealed strong expression of alpha-fetoprotein (AFP), BerEp4, Glypican 3, CK19, and Synaptophysin in absence of OCH1E5, CK7, Chromogranin, CD56, CK5/6, p63, CK20, PLAP and B-HCG (Table 1, Figure 1). Proliferation index (Ki67) was 40\%. Serum carcino-embryonic antigen (CEA) and cancer antigen 19-9 levels were normal, but AFP was elevated to $118.400 \mathrm{IU} / \mathrm{ml}$ (Figure 2A).

After interdisciplinary discussion and with regard to stem/progenitor cell features and high proliferation rate, we decided to treat the patient with chemotherapy according to the FOLFOX-6 regime. After 2 cycles of
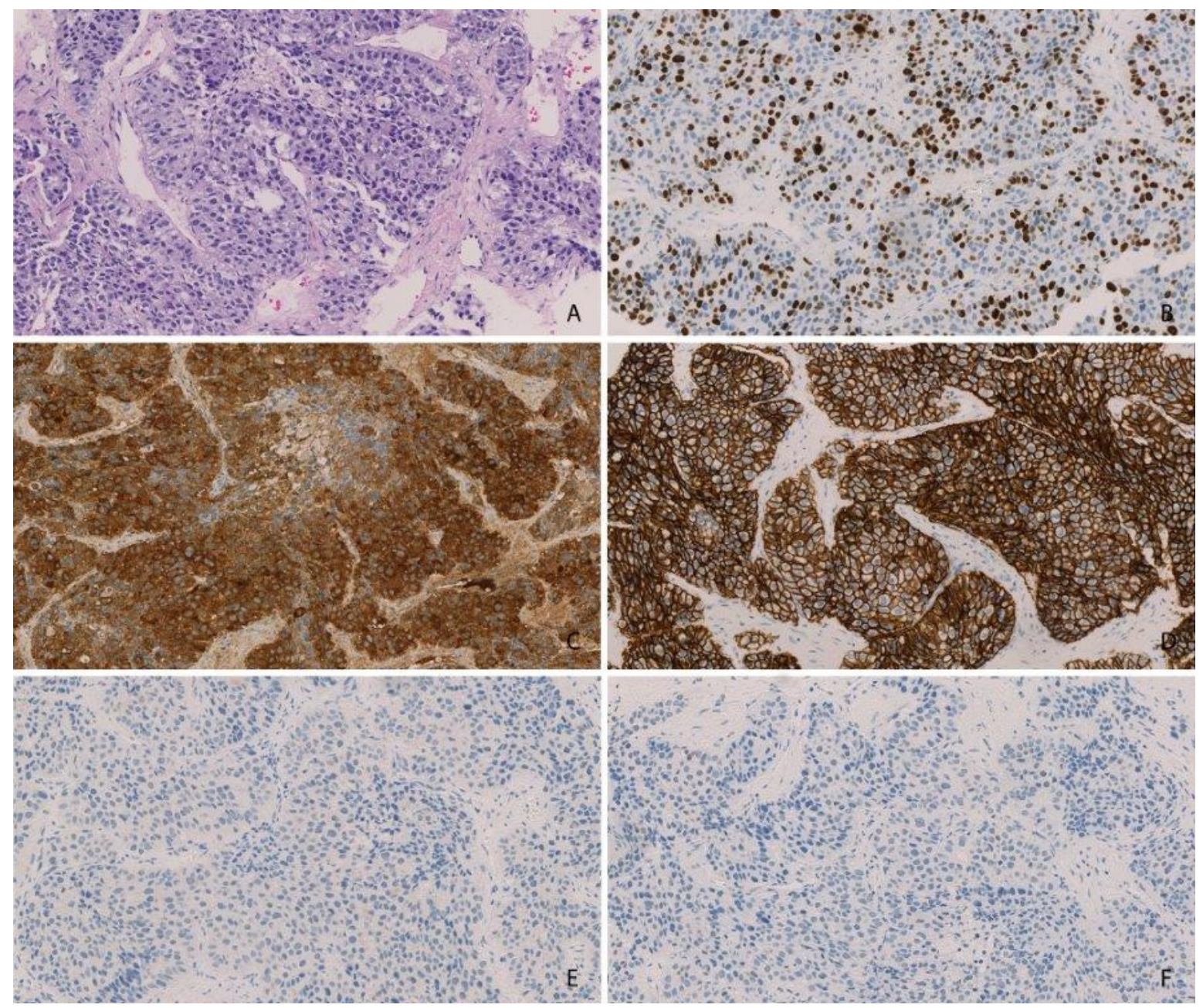

Figure 1: Immunohistochemistry for liver cancers with stem/progenitor cell features. Immunohistochemistry of the liver tumor from patient 1 A. Hematoxylin and Eosin Staining B. Ki67 C. Alpha Feto Protein D. EpCAM E. Cytokeratin 7 F. OCH1E5. 
Table 1: Liver cancers with stem/progenitor cell features express a unique set of proteins

\begin{tabular}{|c|c|c|c|c|}
\hline & Case 1 & Case 2 & Case 3 & \\
\hline Ki67 (\%) & $40 \%$ & $30-90 \%$ & $80 \%$ & proliferation \\
\hline CK7 & - & + & focally + & \multirow{2}{*}{$\mathrm{CC}$} \\
\hline CK19 & in $20 \%+$ & + & + & \\
\hline OCH1E5 (HEPAR1) & - & + & + & \multirow{3}{*}{$\mathrm{HCC}$} \\
\hline Glypican 3 & + & $\mathrm{m}$ & + & \\
\hline AFP & ++ & + & focally + & \\
\hline CD117 (ckit) & focally + & focally + & + & \multirow{3}{*}{ stem cell } \\
\hline BerEp4 (EPCAM) & ++ & + & ++ & \\
\hline CD56 & - & focally + & + & \\
\hline
\end{tabular}

CK: Cytokeratin, CD: Cluster of Differentiation, AFP: Alpha Feto Protein, m: missing.

FOLFOX, CT-scans showed a marked shrinkage of the liver tumor masses (Figure 3A). AFP dropped from $118.400 \mathrm{IU} / \mathrm{ml}$ to $23.196 \mathrm{IU} / \mathrm{ml}$ (Figure 2A). During therapy, the patient had to be admitted to hospital due to complex focal seizures, and 5-FU toxicity was suspected. Anticonvulsive treatment with Valproate and Lamotrigine was started, and no further seizures or neurological events were observed thereafter. Because of the assumed 5-FU toxicity, therapy was changed to Cisplatin and Gemcitabine. Surprisingly, no response to this protocol was observed and AFP increased under therapy. Since $\mathrm{CT}$ also showed progressive disease, chemotherapy was changed to Paclitaxel and Oxaliplatin. Although AFP initially decreased from 138.000 to $88.000 \mathrm{IU} / \mathrm{ml}$, a CTscan after 3 cycles revealed another progression, and at this time AFP had increased to $155.000 \mathrm{IU} / \mathrm{ml}$, reaching the highest value since primary diagnosis. Facing disease progression and with the impressive effect of FOLFOX as first line treatment in mind, we decided to re-treat the patient with 5-FU using the FOLFIRI protocol. This therapy regime again led to a partial remission in the $4^{\text {th }}$ line of treatment and disease stabilization for 4 months (Figure 2A and 3B). AFP dropped to $21.000 \mathrm{IU} / \mathrm{ml}$. However, disease finally progressed after 8 cycles of FOLFIRI-treatment. Therapy was subsequently changed to Gemcitabine in combination with nab-paclitaxel, but did not result in further disease stabilization. The patient died 23 months after first diagnosis.

\section{Patient 2}

This Caucasian female patient presented at the age of 66 years with 2 intrahepatic lesions suspicious for HCC in CT-scan and signs of local peritoneal carcinomatosis. No underlying liver pathologies were present, and the patient was in excellent performance status (KarnofskyIndex $100 \%$, ECOG 0). Liver function was normal, no relevant secondary diagnoses were known (Table 2). The patient underwent laparoscopic surgery with a resection of a tumor mass adherent to the peritoneum in liver segment IVb. Histomorphology showed atypical medium-sized tumor cells with predominantly solid and focally glandular growth pattern, partially separated by prominent strands of fibrous stroma. Areas of tumor necrosis were detectable. Immunohistochemical staining showed positivity of KL1, CK7, CK19, CK8, OCH1E5, BerEp4 and AFP as well as CD117 in absence of CK20. Proliferation index (Ki67) was high (30-90\%) (Table 1). Taken together, we diagnosed a tumor with both, hepatocellular and cholangiocellular differentiation aspects as well as additional characteristics of a stem/progenitor cell tumor. Serum AFP was elevated to $800 \mathrm{IU} / \mathrm{ml}$ at first diagnosis (Figure 2B). A postoperative FDG-PET CT scan revealed no distant metastasis, but primovist-enhanced MR imaging two month later showed a suspicious lesion in liver segment VIII. A diagnostic laparoscopy showed further peritoneal tumor manifestations leaving no option for curative resection. Therefore, after interdisciplinary tumor board decision, palliative chemotherapy with cisplatin and gemcitabine, the standard treatment for $\mathrm{CC}$, was administered for 2 months [3]. First line therapy led to a partial response and a drop of AFP (Figure 2B). Encouraged by the good response to chemotherapy and with regard to the stem/ progenitor-cell features and high proliferation rate of the tumor, chemotherapy was escalated to cisplatin plus etoposide according to the PE-protocol as used for germ cell tumors for 4 cycles, resulting in a radiologic complete remission and a normalization of serum AFP [9]. Despite this success, the patient remained critical of the concept of chemotherapy and disrupted the therapy. After 8 months without therapy, a CT-scan again showed suspicious 
A

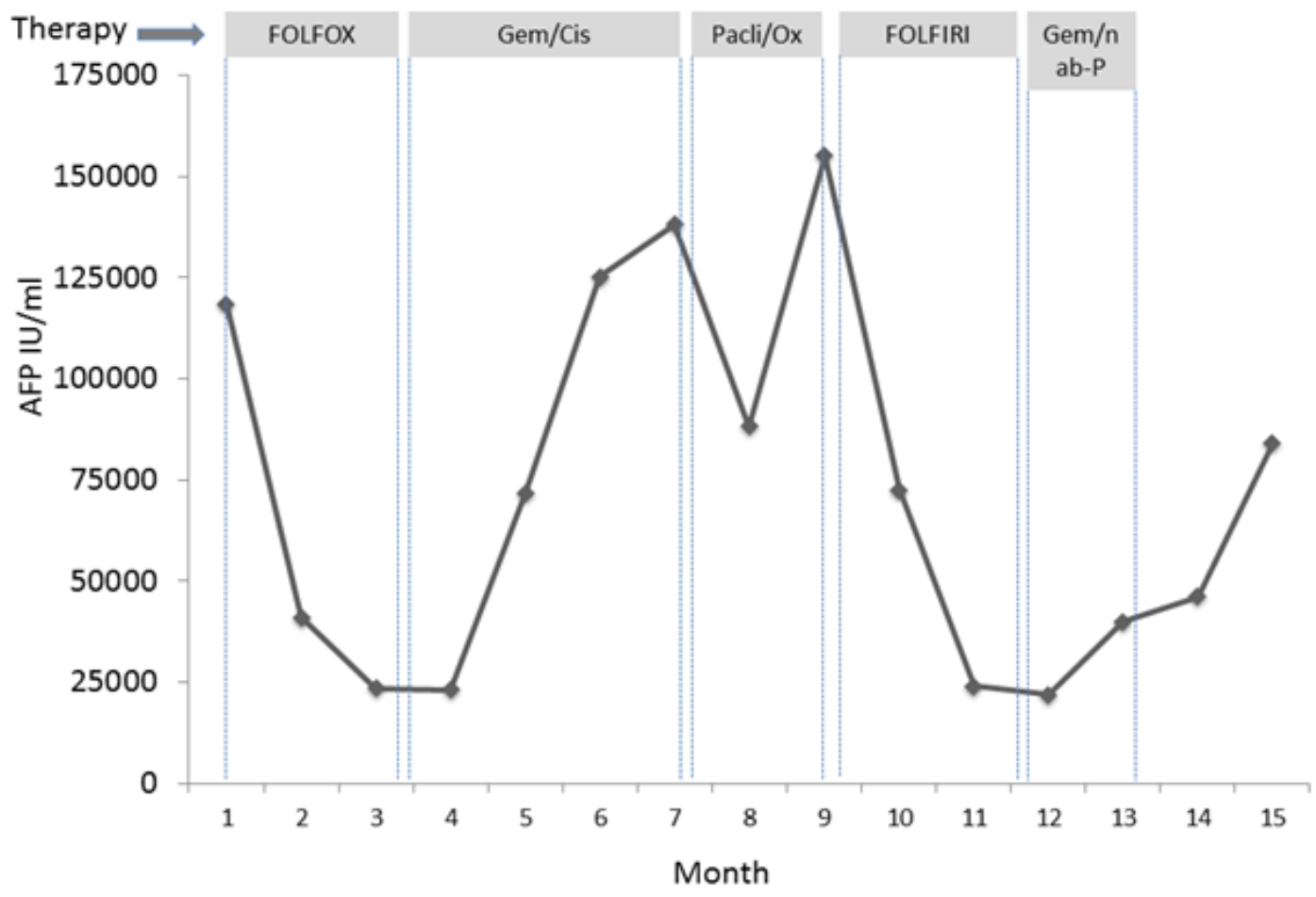

B

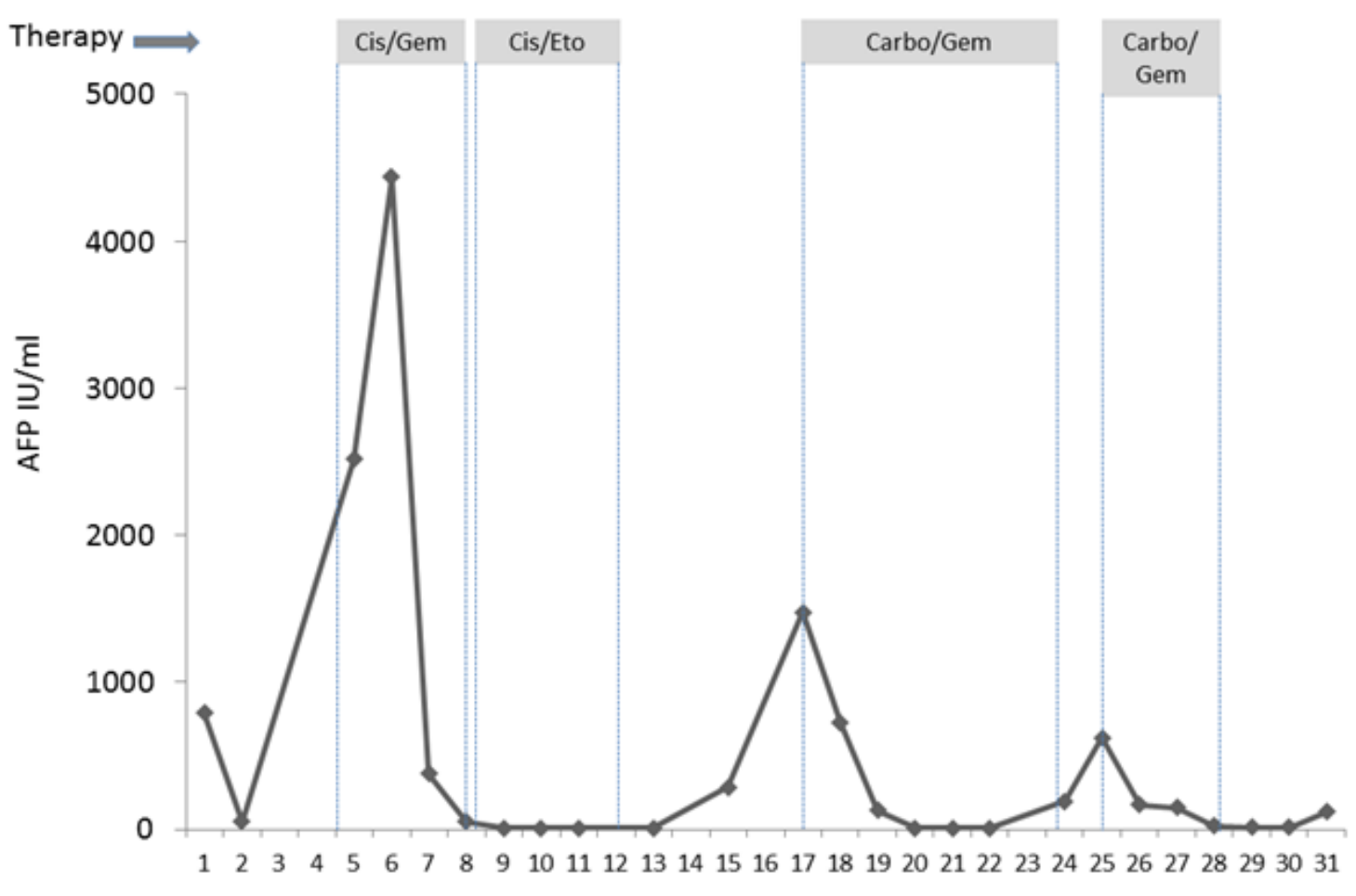

Month

Figure 2: Clinical course of patients 1 and 2 including various chemotherapy regimens and AFP. Serum AFP of patient 1 A. and patient 2 B. during treatment. Grey boxes indicate treatment regime. Gem/Cis: Gemcitabine + Cisplatin, Pacli/Ox: Paclitaxel + Oxaliplatin, Gem/nab-P: Gemcitabine + nab-Paclitaxel, Carbo/Gem: Carboplatin/Gemcitabine. 
Table 2: Baseline laboratory test results for patients at first referral

\begin{tabular}{|l|c|c|c|}
\hline & Patient 1 & Patient 2 & Patient 3 \\
\hline Bilirubin $(0-1 \mathrm{mg} / \mathrm{dl})$ & 0.5 & 0.2 & 1.7 \\
\hline Albumin $(30-50-\mathrm{g} / \mathrm{l})$ & 40.8 & 48.5 & 30.4 \\
\hline INR $(0-1.2)$ & 1.08 & 1.01 & 1.31 \\
\hline ALT $(0-50 \mathrm{U} / \mathrm{l})$ & 54 & 16 & 34 \\
\hline AST $(0-46 \mathrm{U} / \mathrm{l})$ & 50 & 15 & 280 \\
\hline ALP $(40-130 \mathrm{U} / \mathrm{l})$ & 182 & 112 & 661 \\
\hline GGT $(0-60 \mathrm{U} / \mathrm{l})$ & 221 & 25 & 2041 \\
\hline Creatinine $(0.6-1.4 \mathrm{mg} / \mathrm{dl})$ & 0.69 & 0.72 & 1.51 \\
\hline Haemoglobine $(13-17 \mathrm{~g} / \mathrm{dl})$ & 12 & 13.6 & 9.6 \\
\hline
\end{tabular}

INR: International normalized rate, ALT: Alanine transaminase, AST: Aspartate transaminase, ALP: Alkaline phosphatase, GGT: Gamma-glutamyl transpeptidase

peritoneal lesions. Concomitantly, serum AFP increased reaching $1478 \mathrm{IU} / \mathrm{ml}$. Chemotherapy was restarted using carboplatin and gemcitabine. Already after 3 months, the peritoneal lesions had vanished and AFP had dropped into the normal range (8.5 IU/ml, Figure 2B). Again, the patient decided to discontinue therapy. AFP raised again after 4 months, thus chemotherapy with carboplatin and gemcitabine was restarted. Finally, the patient refused further therapy leading to a subsequent disease progression and death 37 months after first diagnosis.
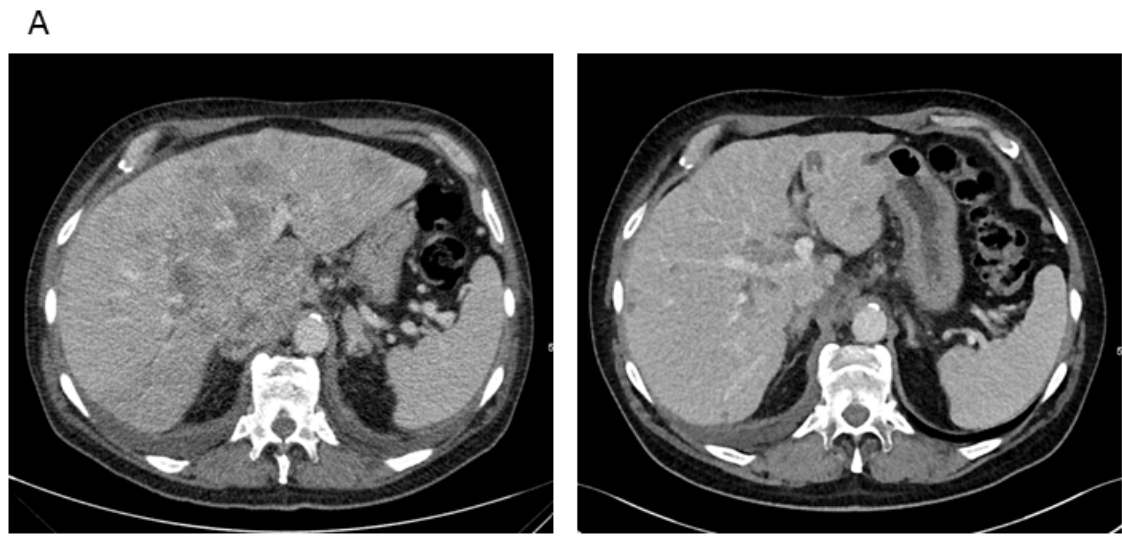

B
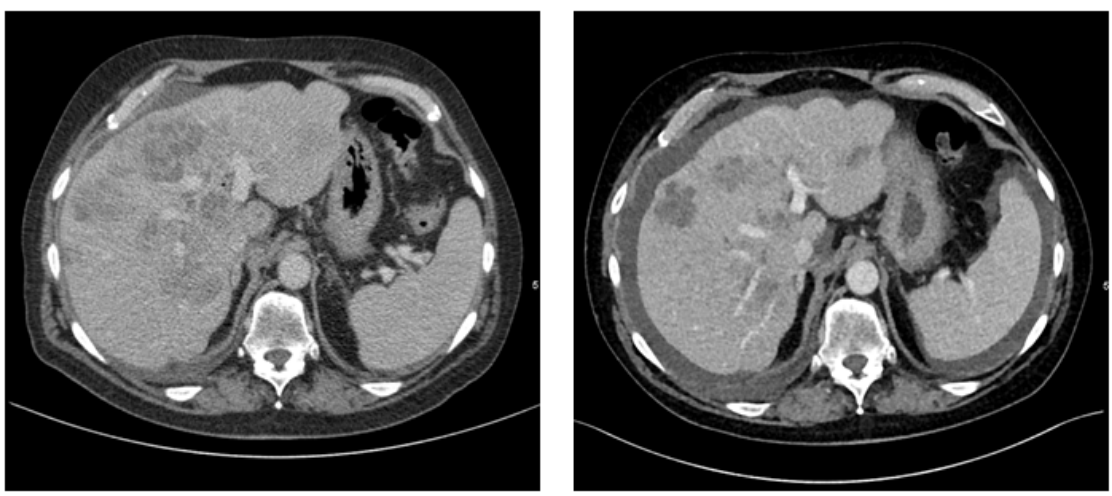

Figure 3: CT-scans reveal a marked response to therapy until the fourth line of treatment (patient 1). A. CT scan before (left) and after (right) induction of first line poly-chemotherapy according to FOLFOX6 protocol. B. CT scan before (left) and after (right) 4 th line chemotherapy according to FOLFIRI protocol. According to RECIST criteria, a partial response with $-36 \%$ calculated for all target lesions was achieved. 


\section{Patient 3}

This 74-year old patient presented in the emergency room complaining of acute abdominal pain and vomiting. $\mathrm{He}$ had a history of weight loss $(15 \mathrm{~kg}$ in the previous four months). Initial blood tests revealed impaired kidney and liver function as well as anemia (Table 2). CT scan showed diffuse tumor infiltration of the liver, lymph node metastases and ascites (Figure 4A, left panel). Ultrasoundguided liver biopsy revealed a highly proliferative (Ki67 $80 \%$ ) liver tumor expressing stem cell markers (BerEp4, Table 1). Serum AFP was elevated to $1240 \mathrm{IU} / \mathrm{ml}, \mathrm{LDH}$ to $1514 \mathrm{U} / \mathrm{I}$ (Figure 4B). The patient had no history of liver disease. At first diagnosis, the general condition of the patient was markedly reduced (Karnofsky-Index 50\%, ECOG 2).
The patient was treated with chemotherapy according to the FOLFOX regime for 6 cycles. During therapy, LDH and AFP decreased, and liver function normalized (Figure 4B). The patient's general condition constantly improved during therapy, and the initial complaints vanished. After 6 cycles of chemotherapy, CT showed dramatic shrinkage of all tumor masses as well as complete disappearance of ascites (Figure 4A, right panel).

\section{DISCUSSION}

Patients with advanced unresectable HCC have a median overall survival of less than 11 months when treated with sorafenib, the only approved drug showing moderate efficacy in this highly therapy resistant

\section{A}
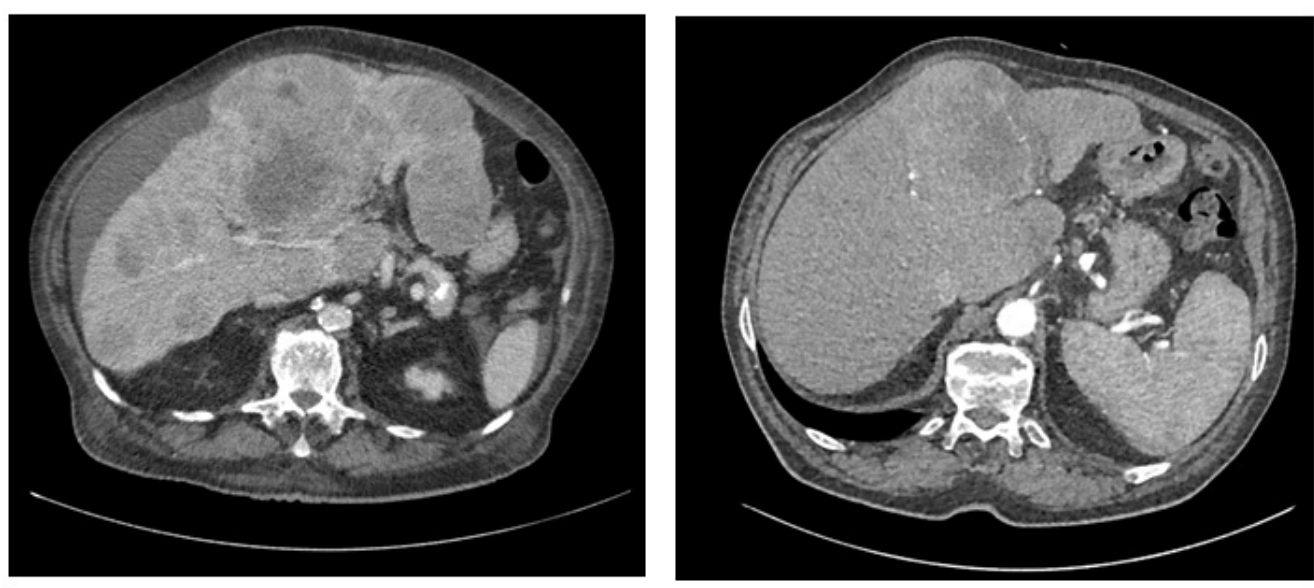

B

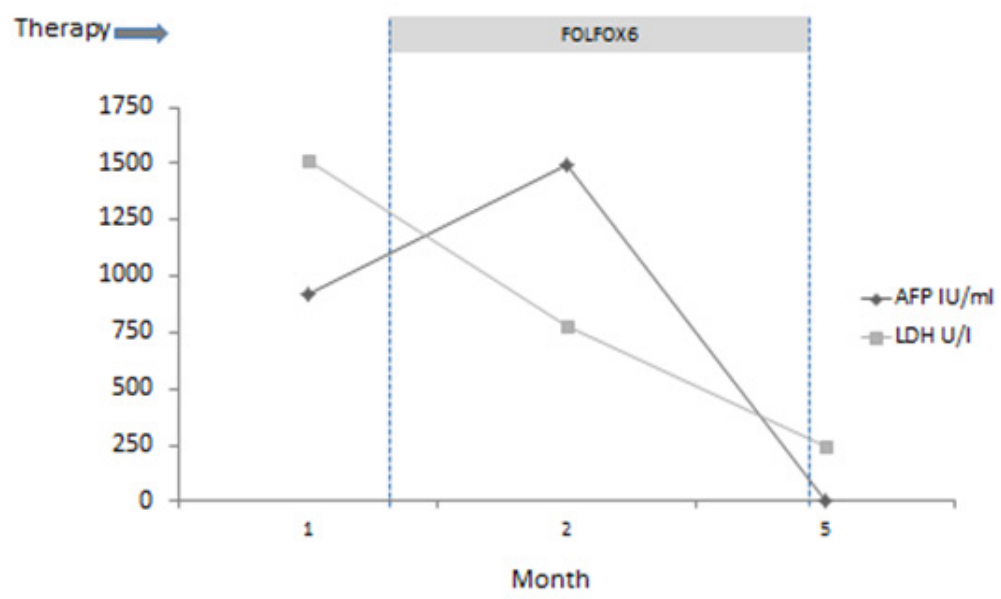

Figure 4: Response to chemotherapy in patient 3. A. CT scan before (left) and after (right) induction of first-line poly-chemotherapy according to FOLFOX protocol. B. LDH and AFP in serum decline to normal during treatment with 6 cycles FOLFOX. 
malignancy [2]. Conventional chemotherapy has shown no significant benefit for patients with HCC [10]. Furthermore, a variety of targeted therapies did not show clinically relevant efficacy for HCC treatment [11, 12]. For advanced intrahepatic CC (ICC), cisplatin and gemcitabine based chemotherapy leads to an overall survival of 11.7 month for advanced CC $[3,13]$. In addition, the emerging concept of immunotherapy is currently under investigation in several clinical trials for $\mathrm{HCC}$ and $\mathrm{CC}[14,15]$. In summary, systemic treatment options for primary liver tumors are restricted and show limited efficacy.

Due to recent liver stem cell/progenitor cell studies, the WHO classification on liver tumors has been revised. The WHO classification of 2010 distinguishes between $\mathrm{HCC}$ and $\mathrm{CC}$ as well as combined $\mathrm{HCC} / \mathrm{CC}$. In addition, combined HCC and $\mathrm{CC}$ (cHCC-CC) are subdivided in a classical type and a stem/progenitor cell type, which has now been considered in the WHO classification [16]. Nevertheless, the classification is provisional in regard to combined $\mathrm{HCC} / \mathrm{CC}$ as its subtyping is pattern-descriptive and currently does not allow for clear classification. In comparison to $\mathrm{CC}$ and $\mathrm{HCC}$, liver tumors with stem cell features have been described as having a more aggressive biological behavior associated with poor prognosis [6, $7,16,17]$. To our knowledge, no clinical studies or case reports addressing therapy for patients with these tumors have been published so far.

In the presented patients, tumors were characterized by histomorphological and immunohistochemical evaluation using a panel of hepatocellular and cholangiocellular differentiation markers. For hepatocellular differentiation, OCH1E5 (Hepatocyte specific antigen 1, Hepar-1) and AFP staining were applied. For cholangiocellular differentiation, cytokeratin (CK) 19, CK7 and CA 19-9 were used. In addition, immunohistochemistry for proteins indicating stem cell features were applied: Epithelial cell adhesion molecule (EpCAM), CD56, CD117 (c-kit). The decision for the right panel of markers is complex, since progenitor cells share several markers with cells of cholangiocytic differentiation (CK19, CK7, EpCAM, CD56). On the other hand, differentiated hepatocytes acquire Hepar-1 and may express AFP, which can be found in hepatic progenitor/ stem cells as well $[8,16,18]$. Therefore, it is commonly accepted that primarily histopathology, supported by a spectrum of markers represents the standard to identify primary liver cancer with stem/progenitor cell features.

Table 1 summarizes histopathological features of the reported patients including a panel of proteins aiming at distinguishing these tumors from conventional $\mathrm{HCC}$ and $\mathrm{CC}$. Of note, proliferation of the tumors was remarkably higher (average $\mathrm{Ki67}$ index $>40 \%$ in all cases) than the proliferation index in classical HCC [19]. Immunohistochemistry revealed positive staining results for CK19, AFP and EpCAM in the presented cases (Table 1, Figure 1).
The unusual histology with stem/progenitor-cell features and high proliferation rate prompted an attempt to treat the patients with chemotherapy. The first two patients survived for 23 and 36 month, which reaches far beyond the life expectancy of patients with systemically treated ICC or HCC. This is remarkable since liver tumors with stem/progenitor cell features have been described as having a more aggressive biological behavior associated with a poorer prognosis compared to ICC and HCC, [6, 8]. Regarding response to therapy according to radiological criteria (mRECIST), we observed two partial responses and a complete remission, respectively. Furthermore, the third patient was first diagnosed with a high and symptomatic hepatic tumor burden causing impaired liver function, ascites and renal failure. After induction of poly-chemotherapy, the dramatic tumor mass shrinkage was accompanied by normalization of the patient's liver function.

These results certainly warrant further studies with chemotherapy in patients suffering from this subgroup of liver cancer. Based on our patients, chemotherapy might be considered if these criteria apply: i) the tumor is according to all imaging, serological, clinical and histopathological data a primary liver cancer that lacks histopathological and immunopathological parameters to categorize it as $\mathrm{HCC}$ or ICC, ii) the tumor has a high proliferation index $(>40 \%)$, iii) the tumor expresses one or more stem cell markers in addition to hepatocellular markers, iv) the tumor arises in non-cirrhotic liver, and v) the tumor marker AFP is elevated. Chemotherapy might even be considered in patients with symptomatic tumor burden and impaired liver function, since the extraordinary susceptibility towards chemotherapy may harbor the potential to recover liver function as seen in the third patient.

However, the choice of chemotherapy may be difficult: while the combination of cisplatin and gemcitabine that is standard for CC worked well in the second patient, the first patient experienced disease progression under the same therapy. The first patient had the best response to 5-FU-based therapies combined with oxaliplatin and irinotecan, and the striking response of the third patient was also achieved with the FOLFOX regimen. The complete response to cisplatin and etoposide of the second patient might even justify the use of aggressive germ cell protocols like PEB (cisplatin, etoposide, bleomycin) or PEI (cisplatin, etoposide, ifosfamide), especially in younger patients [9].

\section{CONCLUSIONS}

Hepatic cancers with stem/progenitor-cell features are an important differential diagnosis especially for tumors arising in otherwise healthy livers. These tumors can only be identified when a biopsy of the tumor is performed and stem cell markers in addition to hepatocellular and/or cholangiocellular markers are 
enclosed. Attempts to treat patients with these tumors with chemotherapy appear to be justified, but the optimal chemotherapy protocol is unclear so far. Further reports on clinical experiences are necessary to finally design rational clinical studies for patients with this rare form of liver cancer.

\section{CONFLICTS OF INTEREST}

There is no conflict of interest.

\section{REFERENCES}

1. Llovet JM, Villanueva A, Lachenmayer A, Finn RS. Advances in targeted therapies for hepatocellular carcinoma in the genomic era. Nat Rev Clin Oncol. 2015; 12: 408-24.

2. Llovet JM, Ricci S, Mazzaferro V, Hilgard P, Gane E, Blanc JF, de Oliveira AC, Santoro A, Raoul JL, Forner A, Schwartz M, Porta C, Zeuzem S, et al, and SHARP Investigators Study Group. Sorafenib in advanced hepatocellular carcinoma. N Engl J Med. 2008; 359:37890 .

3. Valle J, Wasan H, Palmer DH, Cunningham D, Anthoney A, Maraveyas A, Madhusudan S, Iveson T, Hughes S, Pereira SP, Roughton M, Bridgewater J, and ABC-02 Trial Investigators. Cisplatin plus gemcitabine versus gemcitabine for biliary tract cancer. N Engl J Med. 2010; 362:1273-81.

4. Sia D, Villanueva A, Friedman SL, Llovet JM. Liver Cancer Cell of Origin, Molecular Class, and Effects on Patient Prognosis. Gastroenterology. 2017; 152:745-61.

5. Bosman FT, Carneiro F, Hruban RH, Theise ND, Editors:WHO classification of Tumors of the Digestive System. 4th ed. 2010. IARC Press.

6. Guo Z, Li LQ, Jiang JH, Ou C, Zeng LX, Xiang BD. Cancer stem cell markers correlate with early recurrence and survival in hepatocellular carcinoma. World J Gastroenterol. 2014; 20:2098-106.

7. Chan AW, Tong JH, Chan SL, Lai PB, To KF. Expression of stemness markers (CD133 and EpCAM) in prognostication of hepatocellular carcinoma. Histopathology. 2014; 64:93550 .

8. Kim H, Park YN. Hepatocellular carcinomas expressing 'stemness'-related markers: clinicopathological characteristics. Dig Dis. 2014; 32:778-85.

9. Kondagunta GV, Bacik J, Bajorin D, Dobrzynski D, Sheinfeld J, Motzer RJ, Bosl GJ. Etoposide and cisplatin chemotherapy for metastatic good-risk germ cell tumors. J Clin Oncol. 2005; 23:9290-94.

10. Qin S, Bai Y, Lim HY, Thongprasert S, Chao Y, Fan J, Yang TS, Bhudhisawasdi V, Kang WK, Zhou Y, Lee JH, Sun Y. Randomized, multicenter, open-label study of oxaliplatin plus fluorouracil/leucovorin versus doxorubicin as palliative chemotherapy in patients with advanced hepatocellular carcinoma from Asia. J Clin Oncol. 2013; 31:3501-08.

11. Johnson PJ, Qin S, Park JW, Poon RT, Raoul JL, Philip PA, Hsu CH, Hu TH, Heo J, Xu J, Lu L, Chao Y, Boucher E, et al. Brivanib versus sorafenib as first-line therapy in patients with unresectable, advanced hepatocellular carcinoma: results from the randomized phase III BRISK-FL study. J Clin Oncol. 2013; 31:3517-24.

12. Cainap C, Qin S, Huang WT, Chung IJ, Pan H, Cheng Y, Kudo M, Kang YK, Chen PJ, Toh HC, Gorbunova V, Eskens FA, Qian J, et al. Linifanib versus Sorafenib in patients with advanced hepatocellular carcinoma: results of a randomized phase III trial. J Clin Oncol. 2015; 33:172-79.

13. Brandi G, Venturi M, Pantaleo MA, Ercolani G, Fornaro L, Silvestris N, Leone F, Vasile E, Lonardi S, Cereda S, Santini D, Aprile G, GICO. Cholangiocarcinoma: Current opinion on clinical practice diagnostic and therapeutic algorithms: A review of the literature and a long-standing experience of a referral center. Dig Liver Dis. 2016; 48:231-41.

14. Prieto J, Melero I, Sangro B. Immunological landscape and immunotherapy of hepatocellular carcinoma. Nat Rev Gastroenterol Hepatol. 2015; 12:681-700.

15. Rizvi S, Gores GJ. Emerging molecular therapeutic targets for cholangiocarcinoma. J Hepatol. 2017S01688278(17)30197-6.

16. Durnez A, Verslype C, Nevens F, Fevery J, Aerts R, Pirenne J, Lesaffre E, Libbrecht L, Desmet V, Roskams T. The clinicopathological and prognostic relevance of cytokeratin 7 and 19 expression in hepatocellular carcinoma. A possible progenitor cell origin. Histopathology. 2006; 49:138-51.

17. Lee JS, Heo J, Libbrecht L, Chu IS, Kaposi-Novak P, Calvisi DF, Mikaelyan A, Roberts LR, Demetris AJ, Sun Z, Nevens F, Roskams T, Thorgeirsson SS. A novel prognostic subtype of human hepatocellular carcinoma derived from hepatic progenitor cells. Nat Med. 2006; 12:410-16.

18. Yamashita T, Forgues M, Wang W, Kim JW, Ye Q, Jia H, Budhu A, Zanetti KA, Chen Y, Qin LX, Tang ZY, Wang XW. EpCAM and alpha-fetoprotein expression defines novel prognostic subtypes of hepatocellular carcinoma. Cancer Res. 2008; 68:1451-61.

19. D'Errico A, Grigioni WF, Fiorentino M, Baccarini P, Grazi GL, Mancini AM. Overexpression of p53 protein and Ki67 proliferative index in hepatocellular carcinoma: an immunohistochemical study on 109 Italian patients. Pathol Int. 1994; 44:682-87. 